\title{
Similarity of wh-Phrases and Acceptability Variation in wh-Islands
}

\author{
Emily Atkinson *, Aaron Apple, Kyle Rawlins and Akira Omaki \\ Department of Cognitive Science, The Johns Hopkins University, Baltimore, MD, USA
}

In wh-questions that form a syntactic dependency between the fronted wh-phrase and its thematic position, acceptability is severely degraded when the dependency crosses another wh-phrase. It is well known that the acceptability degradation in whisland violation ameliorates in certain contexts, but the source of this variation remains poorly understood. In the syntax literature, an influential theory - Featural Relativized Minimality - has argued that the wh-island effect is modulated exclusively by the distinctness of morpho-syntactic features in the two wh-phrases, but psycholinguistic theories of memory encoding and retrieval mechanisms predict that semantic properties of wh-phrases should also contribute to wh-island amelioration. We report four acceptability judgment experiments that systematically investigate the role of morphosyntactic and semantic features in wh-island violations. The results indicate that the distribution of $w h$-island amelioration is best explained by an account that incorporates

OPEN ACCESS

Edited by: Claudia Felser,

University of Potsdam, Germany

Reviewed by:

Dario Leander Jim Felix Paape University of Potsdam, Germany Ankelien Schippers, Carl von Ossietzky Universität Oldenburg, Germany

${ }^{*}$ Correspondence: Emily Atkinson atkinson@cogsci.jhu.edu

Specialty section: This article was submitted to Language Sciences, a section of the journa Frontiers in Psychology

Received: 31 August 2015 Accepted: 23 December 2015 Published: 12 January 2016

Citation: Atkinson E, Apple A, Rawlins K and Omaki A (2016) Similarity of wh-Phrases and Acceptability Variation in wh-Islands. Front. Psychol. 6:2048. doi: 10.3389/fpsyg.2015.02048 the distinctness of morpho-syntactic features as well as the semantic denotation of the wh-phrases. We argue that an integration of syntactic theories and perspectives from psycholinguistics can enrich our understanding of acceptability variation in whdependencies.

Keywords: relativized minimality, wh-island, D-linking, acceptability judgment, amelioration, similarity interference

\section{INTRODUCTION}

Much work in syntax has investigated the acceptability of English sentences that involve multiple wh-phrases, as in (1):

(1) a. Who _ wondered who bought the car?

b. ${ }^{*}$ What did you wonder who bought _ $?$

Despite the superficial resemblance of sentences in (1), native speakers of English perceive (1a) as a more acceptable sentence of English than (1b). This example illustrates the so-called wh-island constraint (Chomsky, 1964, 1977; cf. Ross, 1967): the grammar disallows dependency formation between the fronted wh-phrase (e.g., what) and its thematic position when there is another intervening $w h$-phrase ( $w h o$ ). The discovery of this constraint raised a number of empirical and theoretical questions that remain unresolved: what types of representational or derivational constraints underlie the $w h$-island phenomenon? Are all $w h$-islands created equal, such that they all produce a similar degree of degradation? If not, what types of linguistic or cognitive factors affect the acceptability variation in $w h$-island violation?

The present paper aims to shed light on these questions through experimental tests of a recent, influential theory of $w h$-islands, called Featural Relativized Minimality (henceforth Featural RM; 
Friedmann et al., 2009; Belletti et al., 2012; Rizzi, 2013; for related proposals, see also Starke, 2001; Boeckx and Jeong, 2003). As the review below illustrates, there are two reasons why this theory deserves ample attention from syntacticians and psycholinguists. First, unlike many syntactic theories that only distinguish grammatical from ungrammatical sentences, Featural RM predicts fine variations in acceptability across different types of $w h$-islands, in particular, how the acceptability of whisland violations can ameliorate depending on the similarity of wh-phrases. Second, as noted by Rizzi (2013), Featural RM resembles memory constraints on sentence processing, where the similarity of competing words in the sentence often predicts comprehension difficulties. As such, empirical investigations of wh-island amelioration effects provide a unique opportunity to explore the link between Featural RM and memory constraints in parsing. We report 4 experiments that explore the empirical predictions of Featural RM, and demonstrate that the theory needs refinement by incorporating aspects of memory encoding and retrieval constraints that guide the real-time computation of syntactic representations.

\section{Featural Relativized Minimality and Similarity Interference in Parsing}

The definition of the Featural RM constraint can be summarized as in (2), which is slightly modified from Rizzi (2013) for expository purposes:

(2) In the configuration $[\ldots X \ldots Z \ldots Y \ldots], X$ and $Y$ cannot form a dependency if $\mathrm{Z}$ c-commands $\mathrm{Y}$, and $\mathrm{Z}$ is the same structural type as X.

The syntactic condition as stated in (2) ensures that a whdependency cannot be established when there is a competing intervener $[\mathrm{Z}$ in (2)] that is structurally closer to the thematic position (Y) than the fronted wh-phrase (X). In Featural RM, the definition of the structural type that constitutes a violation of RM is stated in terms of morpho-syntactic features of those constituents.

A critical empirical observation that led to the use of morphosyntactic features in Featural RM is the amelioration of $w h$-island violations with a $\mathrm{D}$ (iscourse)-linked wh-phrase (Pesetsky, 1987). While D-linked wh-phrases have been intuitively characterized as linked to previous discourse in some way, we will primarily use it here as a cover-term for which-phrases that denote a set of individuals. In the syntax literature, it has been reported that extracting the bare wh-phrase what from the wh-island, as in (3a), results in an ungrammatical sentence, but the extraction of the D-linked wh-phrase which problem in (3b) is considered marginally grammatical. This suggests that the whisland violation in (3b) is somewhat ameliorated, though its acceptability is still degraded compared to the grammatical whextraction in (3c).

(3) a. *What do you wonder who solved __?

b. ?Which problem do you wonder who solved __?

c. Which problem do you think that John solved __?
Assuming the acceptability pattern indicated in (3), Rizzi and colleagues proposed that the degree of overlap in morphosyntactic features of $w h$-phrases accounts for the acceptability variation (Friedmann et al., 2009; Belletti et al., 2012; Rizzi, 2013). For example, the feature relation between the two wh-phrases can be characterized as identity (3a), inclusion (3b), and disjunction (3c). In (3a), the extracted constituent and the intervener both contain only a $[+\mathrm{Q}$ (uestion)] feature, and hence the feature sets are identical. This identity relation results in a severe degradation in acceptability. In (3b), the intervener only contains [+Q], whereas the feature set for the D-linked wh-phrase contains [+Q] as well as $[+\mathrm{N}($ oun $)]$, the latter of which represents the "referential status" of the D-linked wh-phrase (see Cinque, 1990). This configuration is called an inclusion configuration, as the extracted constituent is more richly specified, and its feature set is a superset of that of the intervener. This inclusion relation leads to a less severe degradation in acceptability, and the $w h$-island effect is ameliorated relative to (3a), but the sentence is not necessarily judged as fully acceptable. Finally, in (3c) the embedded clause contains no $[+\mathrm{Q}]$ feature, and hence the feature specifications for the extracted constituent and the (potential) intervener are distinct. This is termed a disjunction configuration, which leads to no violation of Featural RM. These three feature set relations and their well-formedness statuses are summarized in Table $\mathbf{1 .}$

In summary, a key property of Featural RM is that it is concerned with the similarity of the fronted constituent and intervener in terms of morpho-syntactic features: the overlap of features causes degradation, and amelioration is observed when the extracted constituent has a richer or distinct set of morpho-syntactic features than the intervener.

The data discussed above concern the acceptability of sentences, but related observations have been made in adult and child sentence processing research on comprehension of filler-gap dependencies. For example, children experience greater comprehension difficulties with object wh-questions like Which dog did the cat bite __ ? than Who did the cat bite __?, possibly due to the overlap of $[+\mathrm{N}]$ feature in the fronted wh-phrase which dog and the intervening NP the cat (Friedmann et al., 2009; Belletti et al., 2012; for counter-arguments, see Goodluck, 2010; Bentea and Durrleman, 2014). In adult sentence processing, object relative clauses with two definite Noun Phrases (NPs) like The banker that the barber praised __ pose greater comprehension difficulties than sentences in which the intervening NP is replaced by a pronoun or a name, as in The banker that you/John praised_ (Gordon et al., 2001, 2002, 2004, 2006; Warren and Gibson, 2002, 2005). This adult finding may be compatible with Featural $\mathrm{RM}$ if we expand the relevant morpho-syntactic features to

TABLE 1 | Taxonomy of feature set and well-formedness in Featural RM.

\begin{tabular}{lccll}
\hline $\mathbf{X}$ & $\mathbf{Z}$ & $\mathbf{Y}$ & Well-formedness & Type \\
$\begin{array}{l}\text { Fronted } \\
\text { phrase }\end{array}$ & Intervener & $\begin{array}{c}\text { Thematic } \\
\text { position }\end{array}$ & \\
\hline$+\mathrm{A}$ & $+\mathrm{A}$ & $<+\mathrm{A}>$ & Ungrammatical $\left({ }^{*}\right)$ & Identity \\
$+\mathrm{A},+\mathrm{B}$ & $+\mathrm{A}$ & $<+\mathrm{A},+\mathrm{B}>$ & Marginal $(?)$ & Inclusion \\
$+\mathrm{A}$ & $+\mathrm{B}$ & $<+\mathrm{A}>$ & Grammatical $(\sqrt{ })$ & Disjunction
\end{tabular}


include features that distinguish definite NPs from pronouns or names.

An alternative explanation, which has received much support from sentence processing as well as domain-general working memory research, is that these observations reflect constraints on memory encoding and retrieval mechanisms, which are subject to so called similarity-based interference (Lewis and Vasishth, 2005; for a review, see Van Dyke and Johns, 2012). There are two ways in which similarity-based interference could occur. The first and more well-known type of similarity-based interference is retrieval interference. Comprehension of relative clauses or wh-questions requires the parser to retrieve the fronted $w h$-phrase and relate it to its thematic position. According to these memory accounts, this retrieval mechanism uses a cue-based search process, and activates all NPs that meet (some of) the search cues. The retrieval competition among candidates with similar features results in comprehension difficulties. The second type is called encoding interference. This type of interference is observed when the parser encounters words or phrases that are similar to one another, and the process of encoding and storing them as distinct items in memory is disrupted. The resulting representations that are stored in memory may be less precise or robust, and may require more cognitive resources to retrieve later in the sentence (see Gordon et al., 2002).

This raises questions about whether the variation of acceptability judgments in (3) may also be an instance of similarity-based interference: the identity relation in (3a) causes greater similarity-based interference than the inclusion configuration in $(3 \mathrm{~b})$, which in turn causes more interference than (3c). In fact, it may even be possible to reduce Featural RM (Table 1) to constraints on working memory. However, as noted by Rizzi (2013), one key difference between Featural $\mathrm{RM}$ and memory retrieval accounts is that Featural RM is strictly concerned with the overlap of morpho-syntactic features, whereas similarity-based interference is typically sensitive to a variety of similarities, including semantic features (Van Dyke and McElree, 2006; Hofmeister, 2011; Hofmeister and Vasishth, 2014; Kush et al., 2015). Thus, further investigations of the role of semantic overlap in $w h$-island amelioration could shed light on the link between Featural RM and similarity-based interference.

\section{The Present Study}

The present study uses acceptability judgment experiments to explore the role of morpho-syntactic and semantic features in amelioration of $w h$-island violations. Specifically, we will explore the acceptability of the inclusion configuration (4a), and how it compares to the acceptability of the D-linked identity configuration (4b). ${ }^{1}$

(4) a. Which athlete did she wonder who would recruit _ (Inclusion)

b. Which athlete did she wonder which coach would recruit ? (D-linked identity)

In (4a) the extracted $w h$-phrase is D-linked and the intervener is a bare $w h$-phrase, whereas in (4b), both the extracted $w h$-phrase

${ }^{1}$ For a related study in French, see Villata et al. (in press). and the intervener $w h$-phrase are D-linked. Under Featural $\mathrm{RM}$, the dependency in (4b) should be classified as an identity configuration, since both $w h$-phrases have features $[+\mathrm{Q},+\mathrm{N}]$. We will refer to this configuration as D-linked identity, to distinguish it from the typical identity configuration [e.g., (3a)] that only includes bare $w h$-phrases. The dependency in (4a) is an inclusion configuration, since the intervening $w h$-phrase only has the feature $[+\mathrm{Q}]$. Given these assumptions about the morphosyntactic features, Featural RM predicts that (4b) should be less acceptable than (4a). On the other hand, both wh-phrases in the D-linked identity configuration (4b) are semantically more specific, as they characterize distinct sets of individuals: a set of athletes and a set of coaches. The wh-phrases in (4a) are less distinct because they do not denote distinct sets: the set of athletes is a proper subset of the set of people denoted by who. Thus, if semantic distinctness plays a role in dependency formation, the D-linked identity configuration (4b) may cause less similaritybased interference and lead to wh-island amelioration, possibly more so than in the inclusion condition (4a).

Informal judgment data reported in the syntax literature (Pesetsky, 1987, 2000; Comorovski, 1996; Shields, 2008) suggest that the D-linked configuration in (4b) should be more acceptable than the inclusion configuration in (4a); in fact, Pesetsky originally annotated them as fully grammatical, in contrast to non-D-linked identity examples. This may challenge the predictions of Featural RM, but it may reflect the fact that differences such as (4a) vs. (4b) are extremely subtle, and the reliability of the data in (4) may be in question. Although D-linked wh-phrases are reported to ameliorate whisland violations, those sentences are still often described as unacceptable or ungrammatical to some degree. In other words, sentences like (4a) differ from non-D-linked identity sentences only in the severity of degradation, which is not guaranteed to be readily distinguishable in informal judgments. While D-linked identity examples are often (but not uniformly) annotated as fully grammatical in the linguistics literature, there is evidence that they have a different status than nonD-linked identity examples (Pesetsky, 2000; Shields, 2008). For example, Pesetsky (2000) demonstrates that they, unlike regular grammatical multiple-wh examples, e.g., (1a), show intervention effects, e.g., ${ }^{*}$ Which book didn't which person read? Because the contrasts are empirically subtle and complex, we will use acceptability judgment experiments with a 7point scale that provide a quantitative measure of acceptability variation. Such experiments have proven useful for a variety of syntactic phenomena that involve subtle contrasts in acceptability intuitions (e.g., McDaniel and Cowart, 1999; Featherston, 2005; Alexopoulou and Keller, 2007; Hofmeister and Sag, 2010; Sprouse et al., 2012; Sprouse and Hornstein, 2013).

In fact, several experimental studies have provided preliminary evidence that semantic information may indeed play a role in island amelioration (Alexopoulou and Keller, 2013; Goodall, 2015; see also Fanselow et al., 2011). Alexopoulou and Keller (2013) investigated the acceptability of extraction out of whether-islands (e.g., What does Claire wonder whether we will watch _ at the cinema?) while manipulating the animacy 
and D-linking status of the wh-phrase (e.g., what, who, which movie, which colleague). Here, it was found that bare inanimate wh-phrase what was less acceptable than the other three whphrase types, which did not differ from each other. This may suggest that inanimate nouns may be easier to extract out of an island, but this result is difficult to relate to the present study for two reasons. First, the animacy effect did not hold for the D-linked wh-phrases, suggesting that this may not be a robust effect. Second, whether-islands are different from wh-islands in (4) since the intervener (i.e., whether) itself does not relate to another (distant) thematic position. Goodall (2015) found clear evidence that D-linked wh-phrases ameliorate wh-islands that are more similar to those used in the present study. However, his D-linking manipulation compared bare wh-phrase against partitive wh-phrase (What / Which of the cars do you wonder who might buy __ ?). We note that, potentially, this partitive whphrase may have inflated the amelioration effect for a variety of reasons; for example, it contains a richer semantic content, which is known to facilitate retrieval processes in general (Hofmeister, 2011; Hofmeister and Vasishth, 2014). For this reason, our experiments will focus on D-linking manipulation that does not involve the partitive, in line with the D-linking manipulation that has been used more widely in the syntax literature.

Before presenting the experiments, it is important to clarify the scope of the present paper. The similarity-based interference accounts provide the motivation for the present study, as well as the critical predictions that semantic similarity should also play a role in acceptability variation in wh-islands. However, offline acceptability judgment data that we report here does not necessarily shed light on whether the observed acceptability variation in $w h$-islands actually reflects working memory constraints on encoding and retrieval processes during real-time sentence processing. As such, our aim is not to investigate how acceptability variation unfolds during real-time sentence processing, but rather to test whether the ultimate acceptability judgment data is compatible with the predictions of the similarity-based interference accounts. ${ }^{2}$

\section{EXPERIMENT 1}

This experiment investigates the acceptability of wh-island violations with $\mathrm{D}$-linked identity and $w h$-island violations with an inclusion configuration, where only the extracted phrase is D-linked. We test this using a $2 \times 2$ design with movement from within a wh-island (non-island vs. island) and feature relation (non-identity vs. identity) as factors, as in Table 2. The extraction conditions contain extractions out of $w h$-islands. The non-extraction counterparts in do not contain wh-island violations and, hence, serve as baseline conditions.

Featural RM predicts that the D-linked identity condition should be severely degraded because the set of features on both

\footnotetext{
${ }^{2}$ While the present study does not directly tap the real-time generation of acceptability intuition, many studies have shown a correspondence between realtime comprehension difficulties and offline judgment data in processing of fillergap dependencies (see, for example, Gibson and Thomas, 1999; Hofmeister and Sag, 2010; Vasishth et al., 2010; Hofmeister et al., 2013).
}

TABLE 2 | Sample item set from Experiment 1.

\begin{tabular}{|c|c|c|}
\hline \multirow[t]{3}{*}{ Non-identity } & Non-island & $\begin{array}{l}\text { Which student _ wondered who would } \\
\text { invite the visitor? }\end{array}$ \\
\hline & Island & $\begin{array}{l}\text { Which visitor did you wonder who } \\
\text { would invite __? }\end{array}$ \\
\hline & & (Inclusion) \\
\hline \multirow[t]{2}{*}{ Identity } & Non-island & $\begin{array}{l}\text { Which student _ wondered which } \\
\text { teacher would invite the visitor? }\end{array}$ \\
\hline & Island & $\begin{array}{l}\text { Which visitor did you wonder which } \\
\text { teacher would invite __? }\end{array}$ \\
\hline
\end{tabular}

D-linked wh-phrases (which $N P,[+\mathrm{Q},+\mathrm{N}]$ ) are identical. On the other hand, the inclusion configuration should be less degraded than D-linked identity, because the features on the fronted phrase (which $N P,[+\mathrm{Q},+\mathrm{N}]$ ) are a superset of the features on the intervener (who, $[+\mathrm{Q}])$.

\section{Method Participants}

Twenty-five self-reported native English speakers were recruited on the internet via Amazon Mechanical Turk, which has proven to be a useful venue in which participants provide reliable acceptability judgment data (Gibson et al., 2011; Sprouse, 2011). They were paid $\$ 0.30$ for their participation. The data from 3 additional participants was excluded from the analysis, as they only used the extreme ends of the scale in the pre-test phase (see below). This and the following experiments were approved by the Johns Hopkins University Institutional Review Board, and all participants provided informed consent.

\section{Materials}

The stimuli for this experiment consisted of 16 sets of biclausal wh-questions (Table 2). These 16 items were counterbalanced across four lists, so that each participant saw only one version of each target item. Forty-eight filler items of comparable length and varying acceptability were randomly interspersed with these target items for a total of 64 items. Based on our informal judgments and acceptability judgment data in the literature, we manipulated the acceptability of filler items to create three groups of fillers: those that are expected to receive high acceptability rating (good fillers), those that are expected to receive low rating (bad fillers), and sentences whose acceptability was expected to fall in between (middle fillers). Fillers consisted of both declaratives and questions, which were included to ensure that the target items were not the only questions in the experiments. Having filler items with varying acceptability serves two purposes. First, this encourages the participants to use a large portion of the scale, which is critical for revealing subtle contrasts. Second, the data from fillers can serve as a baseline measure that can be used to estimate the magnitude of amelioration effects in target sentences. Stimuli from all four experiments, including the fillers, are provided in Supplementary Materials. 


\section{Procedure}

All of the acceptability judgment experiments in this paper have the same basic procedure. Participants were instructed to rate sentences on a scale from 1 (bad) to 7 (good). Before beginning the experiment, participants were provided with detailed instructions and examples to illustrate that the task is not about stylistic considerations, prescriptive norms, or the plausibility of the event described. This was followed by additional examples with varying degrees of acceptability to illustrate what type of sentence corresponded to different parts of the scale. None of these example sentences used the same structure as the target sentences shown in (5).

Additionally, the first six experimental trials were identical for all participants and served as a pre-test phase. These six trials consisted of two highly acceptable sentences, two highly unacceptable sentences, and two marginal ones. These sentences were included to encourage participants to use the entire scale. The use of a large range of points on the scale was critical for the present study, because the target comparison involves two unacceptable sentence conditions. The acceptability contrast between such sentences may not be revealed if participants used, for example, only the two extreme ends of the scale and treated the task as a binary judgment task. If participants restricted their judgments to the extreme ends of the scale (i.e., 1 and 7) on these initial items, the data from these participants were excluded from further analyses, as it suggests that the participants are treating the scale as if it is a binary choice, which may skew the acceptability ratings in unexpected ways. $^{3}$

\section{Data Analysis}

All experiments in this paper use the same data analysis procedure. First, the raw judgment ratings, including both targets and fillers, were converted to $z$-scores within participants (Schütze and Sprouse, 2013). The $z$-score transformation converts a participant's scores to units that represent the number of standard deviations a particular rating is from that participant's mean rating. This procedure corrects for the potential that individual participants treat the scale differently, e.g., using only a subset of the available ratings, because it standardizes all participants' results to the same scale. We also ran the reported analyses with the raw ratings and the results were unchanged in all experiments, although we will only report data and analyses based on $z$-scores.

Linear mixed-effect models were used to analyze the data; these models allow the simultaneous inclusion of random participant and random item variables (Baayen et al., 2008). Each model was fit using the maximal random effects structure that converged (Barr et al., 2013). These models were run in the $\mathrm{R}$ environment ( $\mathrm{R}$ Core Development Team, 2015) using the lme4 package (Bates et al., 2015). $P$-value estimates

\footnotetext{
${ }^{3}$ The overall pattern in our results did not change when the analysis included participants that would be removed according to this criterion. In this paper, we only present data that excluded those participants, as we think that this exclusion increases the chance of veridically representing the acceptability contrasts between conditions.
}

for the fixed and random effects were calculated using the Sattherwaite approximation in the lmerTest package (Kuznetsova et al., 2015). When the results showed a significant interaction, planned pairwise comparisons were also performed to determine significance between individual conditions. These pairwise comparisons used separate linear mixed-effects models with maximal random effects structure; unlike other statistical analysis methods, mixed-effects models are robust to multiple comparisons.

\section{Results}

Figure 1 presents the $z$-score transformed average ratings for each condition and for each filler type. Good filler sentences were rated as most acceptable (mean $z$-score $=0.80$ ), while bad fillers were rated as least acceptable (mean $z$-score $=-0.75$ ). Middle fillers received ratings near participants' mean rating (i.e., near a $z$-score of 0 , mean $=-0.21$ ). This pattern of acceptability for the fillers is common across all four experiments.

For the target items, we found that the island conditions were rated as less acceptable than the non-island conditions (island mean $z$-score $=-0.71$, non-island mean $z$-score $=-0.05$ ). Within the island conditions, the D-linked identity condition is rated as more acceptable than the inclusion condition $(-0.58$ vs. -0.84 ). In the non-island conditions, average $z$-scored ratings are around zero (means -0.04 and -0.07 ), suggesting that they were rated close to individual participants' mean ratings. This likely reflects the fact that sentences with two wh-phrases are generally uncommon and difficult to process out of context.

Table 3 presents the estimated coefficients and the standard error for the Linear Mixed Effect model with islandhood and feature relation as fixed effects and random intercepts and slopes for participants and items. Significant effects are marked by their beta estimates.

There is a main effect of islandhood such that wh-island violations are significantly less acceptable than non-island violating questions. There is no main effect of feature relation, but there is a significant interaction of islandhood and feature relation. The estimated coefficient of this interaction indicates that the feature combination had a significant effect in the island conditions, but not in the non-island conditions. This is supported by planned pairwise comparisons: the two nonisland conditions are not significantly different from one another $(\beta=-0.02, S E=0.12, p>0.1)$, while the D-linked identity condition is rated as significantly more acceptable than the inclusion condition $(\beta=0.26, S E=0.09, p<0.01)$.

\section{Discussion}

The results indicate that movement out of a $w h$-island generally results in severe degradation of acceptability. More importantly, this degradation is modulated by the feature relation between the two wh-phrases: the $\mathrm{D}$-linked identity condition shows greater acceptability than the D-linked inclusion condition. These results replicate informal acceptability judgments in the literature that D-linking ameliorates $w h$-island effects, as well as judgment contrasts that D-linked identity leads to greater acceptability than inclusion (Comorovski, 1996; Shields, 2008). However, these results are not easily explained by the current formulation of 

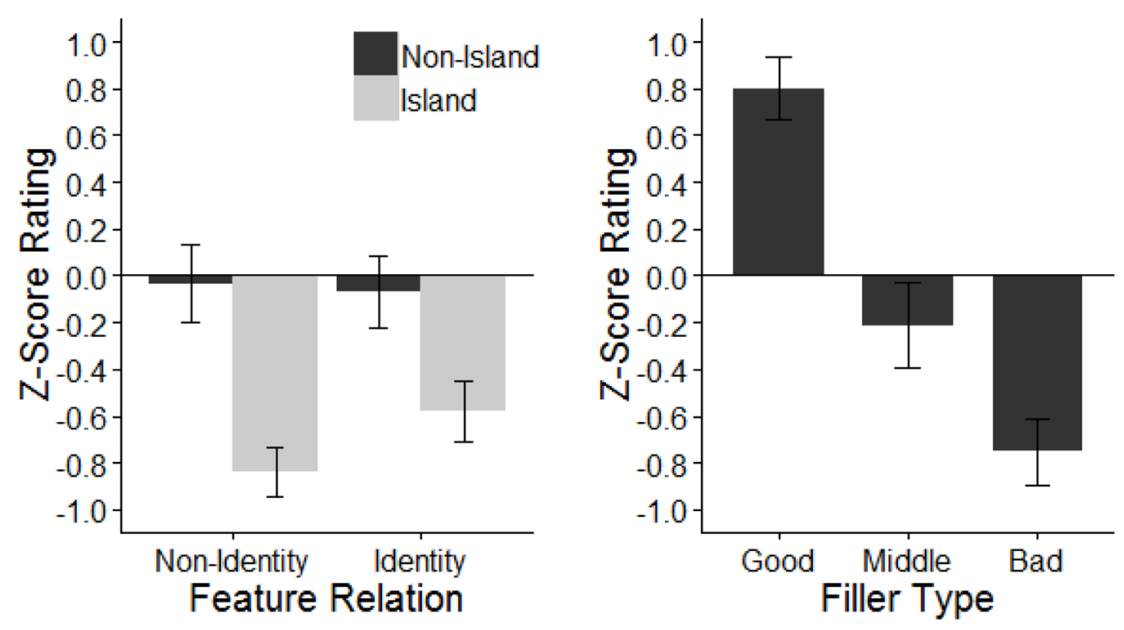

FIGURE 1 | Mean z-score acceptability rating of target questions by wh-phrase combination and islandhood, and mean z-score acceptability rating of filler sentences by filler type. Error bars indicate $\pm 1 \mathrm{SE}$.

Featural RM, which predicted that an identity configuration should be more degraded than an inclusion configuration. In fact, our results indicate that the D-linked identity configuration leads to a greater amelioration of the $w h$-island violation than an inclusion configuration.

We have so far focused only on the D-linked identity configuration. No items in this first experiment involve an identity configuration with bare wh-phrases, even though Rizzi's (2013) proposal critically relies on an acceptability difference between an identity configuration with bare wh-phrases and an inclusion configuration with a fronted, D-linked wh-phrase. In order to confirm the presence of $w h$-island amelioration in the inclusion configuration, as predicted by Featural RM, Experiment 2 compares the inclusion condition against a D-linked identity condition as well as a bare identity condition, where both the fronted wh-phrase and the intervener are bare wh-phrases.

\section{EXPERIMENT 2}

\section{Method}

\section{Participants}

Thirty-two self-reported native English speakers participated via Amazon Mechanical Turk. They were paid $\$ 0.50$ for participating.

TABLE 3 | Fixed effects summary for Experiment 1 with maximal by-participant and by-item random effects.

\begin{tabular}{lcc}
\hline & Estimate & SE \\
\hline Intercept & $-0.38^{* * *}$ & 0.08 \\
Islandhood & $-0.66^{* * *}$ & 0.11 \\
Feature relation & -0.03 & 0.10 \\
Islandhood $\times$ Feature relation & $0.28^{*}$ & 0.13 \\
\hline
\end{tabular}

${ }^{*} p \leq 0.05,{ }^{* *} p \leq 0.01,{ }^{* * *} p \leq 0.001$.

\section{Materials}

The stimuli for this experiment consisted of 24 sets of biclausal sentences, which were constructed by using a $2 \times 2 \times 2$ design with three factors: matrix wh-phrase (bare vs. D-linked), feature relation (non-identity vs. identity), and islandhood (non-island vs. island). The experimental conditions shown in Table 4 include the same four conditions as Experiment 1 (those with a D-linked matrix wh-phrase) as well as four new conditions (those with a bare matrix $w h$-phrase) to test Featural RM's broader predictions for $w h$-island amelioration effects. First, the acceptability of the island conditions is predicted to be significantly lower than that of non-island conditions. Second, Featural RM predicts that the identity island conditions should be the most severely degraded compared to all other conditions, including their non-island counterparts. It also predicts that the magnitude of degradation should not differ between the two identity island conditions. Third, the inclusion configuration should yield an amelioration of $w h$-island violations. Thus, the inclusion condition should yield a degradation compared to its non-island counterpart due to a $w h$-island violation, but the resulting acceptability should still be higher than the island identity conditions. Finally, the reverse inclusion configuration and its non-island counterpart are included in the design to test all combinations of the three factors we used in this experiment. The feature set taxonomy of Featural RM (see Table 1) does not make explicit predictions for these conditions; however, given that Rizzi and colleagues generally attribute the amelioration effects to the supersetsubset relation of feature set between the fronted wh-phrase and intervener, we can infer the predictions of Featural RM to be that the acceptability of the reverse inclusion configuration should be similar to that of the two island identity conditions, and lower than the acceptability of the inclusion condition.

These 24 items were counter-balanced across eight lists, so that each participant saw only one version of a target item. Forty-eight filler items of comparable length and varying acceptability were randomly interspersed with these target items. 
TABLE 4 | Sample item set from Experiment 2.

\begin{tabular}{|c|c|c|c|}
\hline \multirow[t]{6}{*}{ Bare matrix wh-phrase } & Non-identity & Non-island & Who _ wondered which teacher would invite the visitor? \\
\hline & & Island & Who did you wonder which teacher would invite __? \\
\hline & & & (Reverse Inclusion) \\
\hline & Identity & Non-island & Who _ wondered who would invite the visitor? \\
\hline & & Island & Who did you wonder who would invite __? \\
\hline & & & (Bare Identity) \\
\hline \multirow[t]{6}{*}{ D-linked matrix wh-phrase } & Non-identity & Non-island & Which student _ wondered who would invite the visitor? \\
\hline & & Island & Which visitor did you wonder who would invite __? \\
\hline & & & (Inclusion) \\
\hline & Identity & Non-island & Which student _ wondered which teacher would invite the visitor? \\
\hline & & Island & Which visitor did you wonder which teacher would invite __? \\
\hline & & & (D-linked Identity) \\
\hline
\end{tabular}

\section{Procedure and Data Analysis}

This experiment used the same procedure and data analysis steps as Experiment 1. In the statistical analysis, we added planned pairwise comparisons for the island version of the bare identity, inclusion, and D-linked identity conditions, as the comparison of these three conditions is critical for establishing the amelioration of $w h$-island violations that are predicted by Featural RM.

\section{Results}

Similar to Experiment 1, all four island conditions were judged as less acceptable than their non-island counterparts (island mean $z$-score $=-0.54$, non-island mean $z$-score $=0.10$ ), see Figure 2 . Among the non-island conditions, the non-identity bare matrix $w h$-phrase condition received the highest rating (mean $=0.25$ ), but we will leave this aside as it bears no relevance to our goal of testing the predictions of Featural RM. The other nonisland conditions were judged similarly with mean $z$-score ratings around zero (means $-0.03,0.10$, and 0.09). Among the island conditions, the D-linked identity condition was rated as the most acceptable (mean $=-0.38$ ). The remaining three extraction conditions received similar ratings (means $-0.57,-0.58$, and -0.62 ).

The Linear Mixed Effect model analysis confirmed that the overall pattern is consistent with Experiment 1 . Table 5 presents

TABLE 5 | Fixed effects summary for Experiment 2 with by-participant and by-item random intercepts for islandhood, feature relation, and matrix wh-phrase type.

\begin{tabular}{lcc}
\hline & Estimate & SE \\
\hline Intercept & $-0.22^{* * *}$ & 0.05 \\
Islandhood & $-0.64^{* * *}$ & 0.12 \\
Feature relation & -0.02 & 0.06 \\
Matrix wh-phrase & -0.02 & 0.05 \\
Islandhood $\times$ Feature relation & $0.26^{* *}$ & 0.10 \\
Islandhood $\times$ Matrix wh-phrase & -0.09 & 0.10 \\
Feature relation $\times$ Matrix wh-phrase & $-0.26^{* *}$ & 0.10 \\
Islandhood $\times$ Feature relation $\times$ Matrix wh-phrase & 0.01 & 0.19 \\
\hline
\end{tabular}

The maximal random effects model did not converge; this model has random slopes for islandhood, feature relation, and their interaction.

${ }^{*} p \leq 0.05,{ }^{* *} p \leq 0.01,{ }^{* * *} p \leq 0.001$. the estimated coefficients, the standard error, and the estimated $p$-value for the Linear Mixed Effect model with islandhood, feature relation, and matrix wh-phrase as fixed effects and random intercepts for participants and items.

As in Experiment 1, there was a main effect of islandhood, but there was no main effect of either feature relation or matrix wh-phrase. Importantly, there was an interaction of islandhood and feature relation as well as feature relation and matrix wh-phrase, which suggests that the feature relation factor modulates the effects of islandhood or matrix whphrase type on the acceptability. Planned pairwise comparisons among island conditions revealed no significant difference between the bare identity condition and the inclusion condition $(\beta=0.04, S E=0.10, p>0.1)$. This suggests that the D-linking amelioration effect was not observed for the inclusion configuration. Additionally, there was no significant difference between the inclusion and reverse inclusion conditions $(\beta=0.06$, $S E=0.09, p>0.1)$. On the other hand, the D-linked identity condition is significantly more acceptable than the inclusion condition $(\beta=0.23, S E=0.11, p=0.05)$, and marginally more acceptable than the bare identity condition $(\beta=-0.19$, $S E=0.11, p<0.1)$. This pattern suggests that the D-linked identity condition showed a reliable amelioration of $w h$-island violations. As reverse inclusion patterns with inclusion, there is no significant difference between reverse inclusion and bare identity $(\beta=-0.01, S E=0.1, p>0.1)$, but $\mathrm{D}$-linked identity is marginally more acceptable than reverse inclusion $(\beta=0.18$, $S E=0.1, p=0.07)$.

\section{Discussion}

Replicating the findings from Experiment 1, wh-island violations with $\mathrm{D}$-linked identity received a reliably higher acceptability rating than bare identity or inclusion configurations. Furthermore, there was no clear evidence for amelioration of the $w h$-island violation in the inclusion condition. This selective wh-island amelioration effect is, again, not easily explained by Featural RM, which predicts that the inclusion configuration should be rated as more acceptable than bare or D-linked identity conditions. Finally, the finding that inclusion and reverse inclusion do not differ in acceptability also conflicts with the predictions of Featural RM. 
The absence of an amelioration effect in the inclusion condition was surprising, given that amelioration effects in the inclusion configuration have been widely reported in the literature (Pesetsky, 1987; Cinque, 1990; Alexopoulou and Keller, 2013; Goodall, 2015). Experiment 3 explores whether the animacy of $w h$-phrases may play a role in amelioration of wh-island violations.

\section{EXPERIMENT 3}

Experiment 2 provided no evidence for wh-island amelioration in the inclusion configuration. One plausible source of this unexpected finding is the number of animate nouns in the stimuli. Examples for $w h$-island amelioration in the literature typically included a single animate $w h$-phrase (5a), whereas the stimuli used in Experiment 2 (5b) included two animate whphrases.

(5) a. Which book did you persuade which person to read _ ? (Pesetsky, 1987)

b. Which athlete did you wonder who would recruit __? (from Table 3)

It is plausible that having two animate wh-phrases makes them less distinct from one another, which may have increased confusability or processing demands in our stimuli. As discussed above, this is predicted by the similarity-based interference approach. In order to address this question, Experiment 3 replaces the animate wh-phrase [e.g., which athlete in (5b)] with an inanimate $w h$-phrase to more closely resemble the examples from the literature.

\section{Method}

\section{Participants}

Thirty-one self-reported native English speakers participated via Amazon Mechanical Turk. They were paid $\$ 0.50$ for completing the task.

\section{Materials}

The stimuli for this experiment consisted of 24 sets of biclausal sentences, following the same $2 \times 2 \times 2$ design used in
Experiment 2, with three factors: islandhood, feature relation, and matrix wh-phrase (see Table 6). The non-island conditions were identical to those in Experiment 2, where the matrix whphrase was animate. In the new island conditions, on the other hand, the fronted wh-phrase was changed from an animate to an inanimate noun (e.g., which event). Because the animacy of the fronted NP has changed, what replaces who as the bare matrix wh-word in the bare identity and reverse inclusion conditions (i.e., What did you wonder. . ?).

The 24 items were counter-balanced across eight lists, such that each participant saw only one version of each. Forty-eight filler items of comparable length and varying acceptability were randomly interspersed with these target items for a total of 72 items.

\section{Procedure and Data Analysis}

The procedure and data analysis method were identical to those of Experiment 2.

\section{Results}

The acceptability judgment pattern in this experiment (Figure 3) resembles that of Experiment 2, as the D-linked identity condition received the highest rating among the extraction conditions $(-0.06$ vs. $-0.62,-0.83$, and -0.60$)$.

These data were submitted to Linear Mixed Effect model analyses, which used islandhood, feature relation, and matrix whphrase as fixed effects and random intercepts for participants and items. The coefficient estimates, standard error, and estimated p-values are presented in Table 7.

The results revealed the same main effect of islandhood as in the previous experiments due to the decreased acceptability of the island violating conditions (island mean $=-0.52$, nonisland mean $=0.11)$. Also, all three of the pairwise interactions are significant: islandhood and feature relation, islandhood and matrix wh-phrase, and feature relation and matrix wh-phrase. This suggests that all of these factors influence acceptability, even though the three-way interaction is not significant.

Next, following the data analysis procedure in Experiment 2, planned pairwise comparisons of the island conditions were conducted in order to examine the precise distribution of the amelioration effect. Replicating the results

TABLE 6 | Sample item set from Experiment 3.

\begin{tabular}{|c|c|c|c|}
\hline \multirow[t]{2}{*}{ Bare matrix wh-phrase } & Non-identity & $\begin{array}{l}\text { Non-island (Animate) } \\
\text { Island (Inanimate) }\end{array}$ & $\begin{array}{l}\text { Who _ wondered which family should host the event? } \\
\text { What did you wonder which family should host__? } \\
\text { (Reverse Inclusion) }\end{array}$ \\
\hline & Identity & $\begin{array}{l}\text { Non-island (Animate) } \\
\text { Island (Inanimate) }\end{array}$ & $\begin{array}{l}\text { Who _ wondered who should host the event? } \\
\text { What did you wonder who should host__? }\end{array}$ \\
\hline \multirow[t]{2}{*}{ D-linked matrix wh-phrase } & Non-identity & $\begin{array}{l}\text { Non-island (Animate) } \\
\text { Island (Inanimate) }\end{array}$ & $\begin{array}{l}\text { Which graduate _ wondered who should host the event? } \\
\text { Which event did you wonder who should host__? }\end{array}$ \\
\hline & Identity & $\begin{array}{l}\text { Non-island (Animate) } \\
\text { Island (Inanimate) }\end{array}$ & $\begin{array}{l}\text { Which graduate _ wondered which family should host the event? } \\
\text { Which event did you wonder which family should host__? }\end{array}$ \\
\hline
\end{tabular}




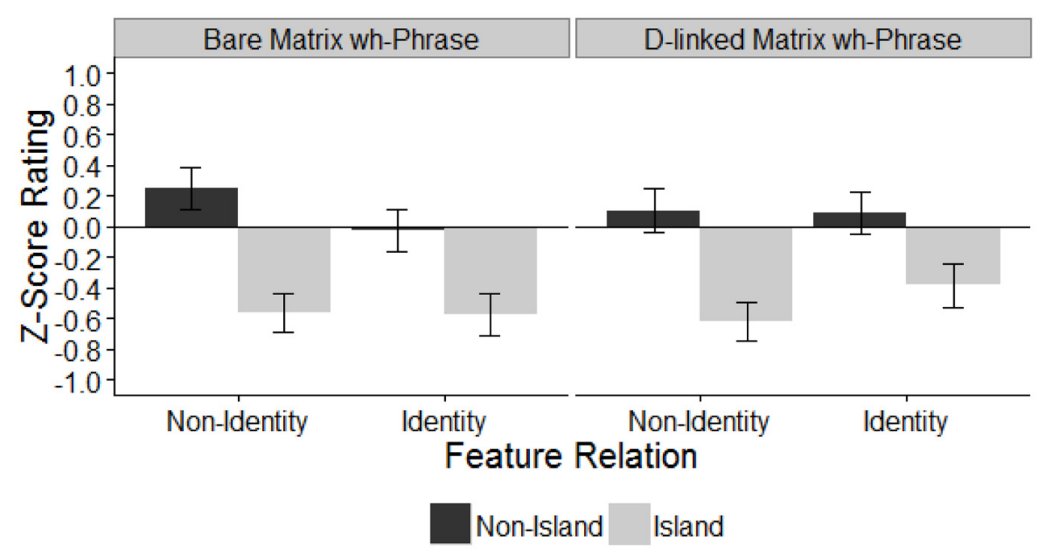

FIGURE 2 | Mean z-score acceptability rating in Experiment 2. Error bars indicate \pm 1 SE.

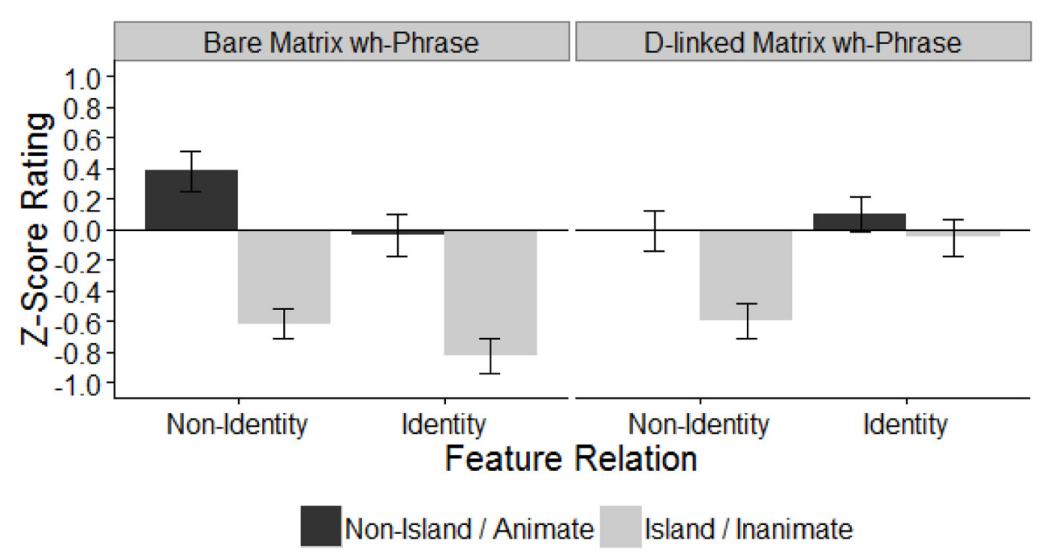

FIGURE 3 | Mean z-score acceptability rating in Experiment 3. Error bars indicate \pm 1 SE.

of our previous experiments, the D-linked identity condition is significantly more acceptable than the inclusion condition $(\beta=0.54, S E=0.09, p<0.001)$ as well the bare identity condition $(\beta=0.78, S E=0.12, p<0.001)$. Also replicating Experiment 2, no difference was found between the inclusion and reverse inclusion conditions $(\beta=0.02, S E=0.09, p>0.1)$. Importantly, unlike Experiment 2, we found that the inclusion condition is significantly more acceptable than the bare identity condition $(\beta=-0.23, S E=0.09, p<0.05)$. Again, reverse inclusion patterns with inclusion, so it is significantly more acceptable than bare identity $(\beta=-0.21, S E=0.09, p<0.05)$ and marginally less acceptable than D-linked identity $(\beta=0.13$, $S E=0.07, p=0.07)$.

\section{Discussion}

Once again, this experiment found that the D-linked identity condition was more acceptable than the other island conditions. Also, the reverse inclusion conditions patterned with the inclusion conditions. Unlike Experiment 2, however, we found evidence for wh-island amelioration in the inclusion configuration, as the inclusion island condition was judged as more acceptable than the bare identity island condition. The fact that this effect was only found in Experiment 3 could be taken to suggest that the animacy manipulation plays a critical role in its emergence.

However, there are reasons to be cautious of this interpretation. In Experiment 3, island and animacy factors were confounded as the fronted wh-phrases were always inanimate in the island conditions. This design does not allow a direct comparison of $w h$-island violations with fronted animate wh-phrases to those with inanimate ones. Experiment 4 explores this issue by manipulating animacy within the island conditions.

\section{EXPERIMENT 4}

This experiment manipulates animacy and feature relation as in Table 8, in order to investigate whether $w h$-island amelioration in inclusion configurations is directly conditioned by the animacy of the fronted wh-phrase.

This allowed us to investigate the extent to which animacy contributed to wh-island amelioration effects. Given the results of Experiment 3, we predicted that the contrast between the 
TABLE 7 | Fixed effects summary for Experiment 3 with by-participant and by-item random intercepts for extraction type, feature relation, and matrix wh-phrase type.

\begin{tabular}{lcc}
\hline & Estimate & SE \\
\hline Intercept & $-0.21^{* * *}$ & 0.04 \\
Islandhood & $-0.63^{* * *}$ & 0.08 \\
Feature relation & 0.02 & 0.06 \\
Matrix wh-phrase & $0.14^{* *}$ & 0.05 \\
Islandhood $\times$ Feature relation & $0.31^{* *}$ & 0.11 \\
Islandhood $\times$ Matrix wh-phrase & $0.52^{* * *}$ & 0.09 \\
Feature relation $\times$ Matrix wh-phrase & $0.62^{* * *}$ & 0.09 \\
Islandhood $\times$ Feature relation $\times$ Matrix wh-phrase & 0.25 & 0.19 \\
\hline
\end{tabular}

The maximal random effects model did not converge; this model has random slopes for islandhood, feature relation, and their interaction.

${ }^{*} p<0.05,{ }^{* *} p<0.01,{ }^{* * *} p<0.001$.

TABLE 8 | Sample item set from Experiment 4.

\begin{tabular}{lll}
\hline Animate & $\begin{array}{l}\text { Bare Identity } \\
\text { Inclusion }\end{array}$ & $\begin{array}{l}\text { Who did you wonder who should host__? } \\
\text { Which visitor did you wonder who should host__? }\end{array}$ \\
\hline Inanimate & $\begin{array}{l}\text { Bare Identity } \\
\text { Inclusion }\end{array}$ & $\begin{array}{l}\text { What did you wonder who would host___? } \\
\text { Which event did you wonder who should host __? }\end{array}$ \\
\end{tabular}

inclusion and bare identity conditions should only appear in conditions with an inanimate wh-phrase.

\section{Method}

\section{Participants}

Twenty-nine self-reported native English speakers participated via Amazon Mechanical Turk. They were paid $\$ 0.50$ for completing the experiment. Three additional participants were excluded for using a single value $(n=1)$ or only the extremes of the scale $(n=2)$ during the calibration items.

\section{Materials}

The stimuli for this experiment consisted of 24 sets of biclausal sentences with a $2 \times 2$ design (Table 8), using animacy of the matrix wh-phrase (animate vs. inanimate) and feature relation (bare identity vs. inclusion) as factors. These items were largely based on stimuli from the previous experiments. The 24 test items were counter-balanced across four lists, such that each participant only rated a single item from each set. The addition of 48 length-matched filler sentences resulted in a total of 72 items.

\section{Procedure and Data Analysis}

The procedure and data analysis method were identical to those of previous experiments. Regardless of the presence of a significant interaction, planned pairwise comparisons of feature relation within animacy were conducted to directly test whether the amelioration effect of inclusion was modulated by animacy of the fronted wh-phrase.

\section{Results}

Figure 4 presents the mean $z$-score ratings in each condition. Overall, inanimate $w h$-phrase conditions are rated as more acceptable than those with animate wh-phrases

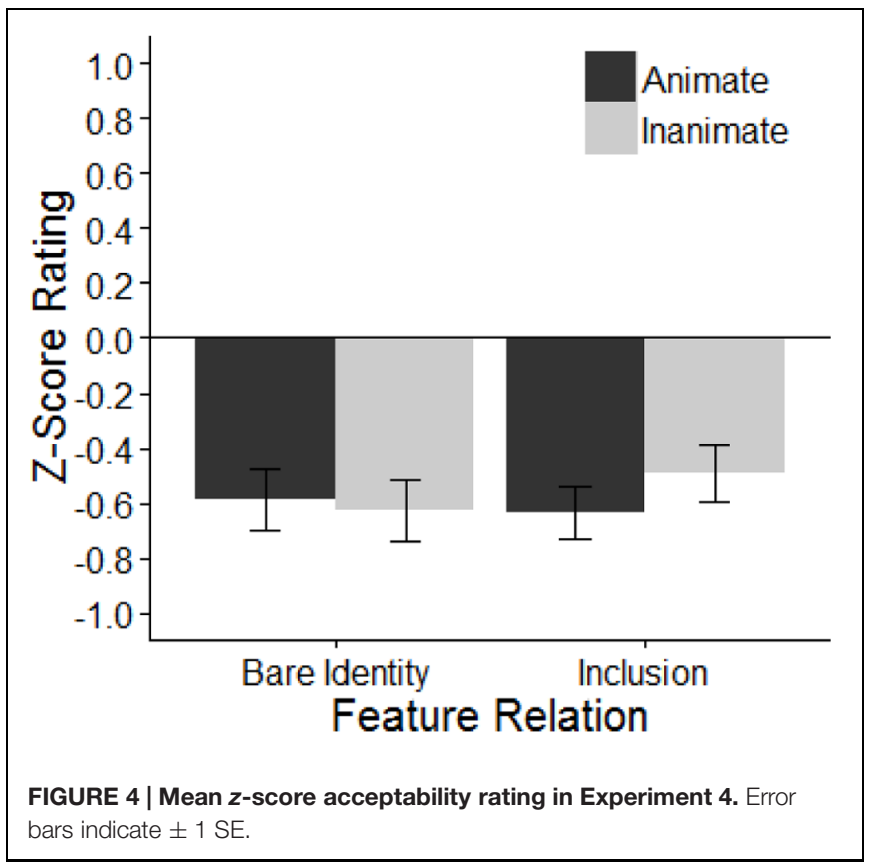

(inanimates $=-0.55$, animates $=-0.61$ ), but the bare identity and inclusion conditions show little difference in their acceptability ratings (bare identity $=-0.59$, inclusion $=-0.57$ ). Within the animate conditions, bare identity and inclusion show little difference in their acceptability ratings $(-0.59$ vs. $-0.63)$. Within the inanimate conditions, however, inclusion was rated as more acceptable than bare identity $(-0.51$ vs. $-0.60)$.

These data were analyzed using a Linear Mixed Effect model analysis with feature relation and animacy as fixed effects. The coefficient estimates, standard error and estimated $p$-values are given in Table 9.

The model revealed no main effect of animacy or feature relation, but there was a marginal interaction between the two factors. Planned pairwise comparisons revealed that inclusion was marginally more acceptable than bare identity when the extracted $w h$-phrase was inanimate (inanimate: $\beta=0.13$, $S E=0.07, p<0.1)$, but not when the extracted phrase was animate $(\beta=-0.04, S E=0.07, p>0.1)$.

\section{Discussion}

This experiment investigated whether the animacy distinctness between two wh-phrases is a pre-requisite for wh-island amelioration in inclusion configurations. The results provide weak support for this hypothesis: when the fronted wh-phrase was animate, there was little difference between bare identity and inclusion conditions, but there was a marginal difference between these configurations when the fronted wh-phrase was inanimate. This finding has two implications. First, the results of Experiments 3 and 4 taken together suggest that the animacy of the extracted $w h$-phrases can modulate $w h$-island amelioration effects, but that the effect can be weak. Second, wh-island amelioration in inclusion configurations is generally not as robust 
as it has been reported in the literature; a weak amelioration may emerge when the fronted $w h$-phrase and intervener are distinct in animacy, but its effect is clearly not as consistently present as the amelioration effect observed in D-linked identity configuration in Experiments 1 through 3.

\section{GENERAL DISCUSSION}

The main goal of this study was to investigate the distribution of $w h$-island amelioration effects, and the extent to which they are modulated by morpho-syntactic and semantic features of wh-phrases. Specifically, we tested the acceptability of a whisland violation involving two D-linked $w h$-phrases (i.e., D-linked identity) against violations with an intervening bare $w h$-phrase (i.e., inclusion) or with no D-linked wh-phrases (i.e., bare identity).

There are two main findings from the experiments reported above. First, we found consistent evidence against the predictions of Featural RM about D-linked identity configurations: such configurations reliably led to a higher acceptability than inclusion configurations. Featural RM predicts the opposite. Moreover, a study that was conducted in parallel in French used a similar design to our Experiment 3 and found the same pattern (Villata et al., in press). Thus, the increased acceptability of the D-linked identity configuration is robust across experiments and across English and French.

Second, we found that the D-linking amelioration effect for wh-island violations can be modulated by animacy, although the animacy effects were not always robust. Experiment 2 used only animate $w h$-phrases and found no evidence for whisland amelioration in the inclusion configuration. Experiment 3 used inanimate nouns for extracted wh-phrases, and revealed evidence for amelioration in the inclusion configuration. This contrast between the experiments suggests that animacy might play a role. However, this effect did not hold robustly in Experiment 4, which showed that the amelioration effect was somewhat stronger for inclusion configuration than bare identity condition, which in turn showed no sign of amelioration regardless of the animacy manipulation. While a complete understanding of the role of animacy or the status of the inclusion configuration awaits further research, it is safe to conclude at this point that the $w h$-island amelioration effects for the inclusion configuration are not as robust as it has been reported in the literature.

TABLE 9 | Fixed effects summary for Experiment 4 with by-participant and by-item random intercepts for feature relation and animacy of the matrix wh-phrase.

\begin{tabular}{lcc}
\hline & Estimate & SE \\
\hline Intercept & $-0.59^{* * *}$ & 0.05 \\
Feature relation & -0.05 & 0.06 \\
Animacy & 0.05 & 0.05 \\
Feature relation $\times$ Animacy & $-0.18 \dagger$ & 0.11 \\
\hline
\end{tabular}

$\dagger p \leq 0.1,{ }^{*} p \leq 0.05,{ }^{*} p \leq 0.01,{ }^{* * *} p \leq 0.001$.
These findings are summarized in (6), which depicts the ranking of acceptability variation among the $w h$-island violations that were examined in this paper. We will now discuss the theoretical implications of these findings.

(6) Bare identity $\leq$ (Reverse) inclusion with an animate whphrase extraction $\leq$ (Reverse) inclusion with an inanimate wh-phrase extraction $<$ D-linked identity $\leq$ no extraction

\section{Implications for Featural RM}

Our data suggests that Featural RM does not fully account for the distribution of $w h$-island amelioration effects, especially the fact that the D-linked identity configuration led to a robust amelioration effect. We do not present this as an argument against Featural RM per se, but minimally something else must be said to account for the behavior of D-linked wh-items beyond the inclusion/identity featural distinction. One potential implication is that the set of morpho-syntactic features assumed in papers by Rizzi and colleagues may need to be enriched. We will explore below the addition of Topic or Animacy features, but demonstrate that neither of these features provides a satisfactory explanation.

Rizzi (personal communication) suggests that the extracted D-linked $w h$-phrase has a [+Topic] feature that the intervening D-linked $w h$-phrase does not, as this feature is only licensed by the left periphery of the matrix clause (for a similar suggestion that the extracted $w h$-phrase may have a presupposition feature, see Grohmann, 2000; Boeckx and Jeong, 2003). If this is the case, then the sentences with two D-linked phrases are cases of inclusion rather than identity (7).

(7) Which athlete did you wonder which coach would recruit $\stackrel{?}{[+\mathrm{Q},+\mathrm{N},+ \text { Topic }] \quad[+\mathrm{Q},+\mathrm{N}] \quad[+\mathrm{Q},+\mathrm{N},+ \text { Topic }]}$

This amendment allows Featural RM to account for the increased acceptability of the D-linked identity configuration. However, this featural augmentation does not explain why this configuration should be reliably more acceptable than the inclusion condition with a bare wh-phrase in the intervener position. Given the feature sets assumed in (7), both of these configurations are inclusion configurations, which are not predicted to show a contrast in acceptability. If we were to grade acceptability based on the degree of featural overlap, the prediction would again go the wrong direction: the bare inclusion condition should have less featural overlap, and therefore be more acceptable than the D-linked identity condition under the analysis in (7).

Another morpho-syntactic feature that may deserve to be added to the Featural RM framework is an animacy feature. It is typically assumed that animacy features do not actively participate in syntactic operations in English. However, animacy is known to play important roles in syntax of other languages (e.g., Slavic languages, see Rappaport, 2003). Our observations of superior $w h$-island amelioration effects for inanimate $w h$-phrases may be the first evidence that animacy plays an important role in English syntax as well. However, the addition of an animacy feature with the same status as e.g., $[+Q]$ above is not fully 
motivated by our data either. First, it offers no explanation for the observed acceptability contrast between the D-linked identity and inclusion configuration in Experiments 1 and 2. Second, using animacy features in Experiment 3 would change the D-linked identity feature relation to that of a reverse inclusion, as shown in (8). Under this configuration, Featural RM predicts the sentence to be equally as degraded as identity configurations, which is the opposite of what was found in Experiment 3. Rather, if Experiment 3 is taken at face value, (8) should be ameliorated simply because the two D-linked wh-phrases have a different value for animacy.

(8) Which award did you wonder which actress should receive

$$
\stackrel{?}{[+} \mathrm{Q},+\mathrm{N}] \quad[+\mathrm{Q},+\mathrm{N},+ \text { animate }] \quad[+\mathrm{Q},+\mathrm{N}]
$$

Finally, incorporating an animacy feature would predict that animacy based amelioration effects hold robustly across all whisland violations, but this prediction is inconsistent with the observation in Experiment 4 that the animacy manipulation showed a selective, weak modulation of the acceptability of the inclusion conditions but not the bare identity configuration. While an animacy distinction is clearly relevant, it cannot easily be captured in featural terms.

In summary, it is not obvious what featural adjustments could account for the amelioration patterns we have shown in this paper in a way that is entirely internal to the principles of Featural RM. ${ }^{4}$ If this effect cannot be accounted for with featural manipulations, then (minimally) something external to the featural system must lead to the amelioration pattern.

\section{Memory Constraints and Semantic Distinctness in Acceptability Variation}

More generally, these results present a challenge to any account of $w$ h-island effects that assumes that D-linked identity examples are acceptable or fully amelioriated: the variable amelioration effect for even this case suggests that some constraint like Relativized Minimality may well be active (in contrast to accounts of D-linking that simply assign it a different LF where the constraint leading to the violation is not at play; Pesetsky, 1987, 2000 on superiority). An explanation for the distribution of $w h$-island amelioration effects in our experiments must take into account the superior amelioration effects in D-linked identity configurations, as well as the fact that extraction of an inanimate $w h$-phrase sometimes leads to a further increase in acceptability. Before we present such explanations, we first argue for a new descriptive generalization: the degree of semantic distinctness of the extracted $w h$-phrase and the intervener (rather

\footnotetext{
${ }^{4}$ One reviewer suggested the inclusion of both a topic and an animacy feature. In example (8), this would result in a configuration known as intersection, where the fronted $w h$-phrase and the $w h$-intervenor have distinct sets of features that share a subset (in the terms of Table 1 , the fronted phrase is $[+A,+B]$ and the intervener is $[+A,+C]$ ) (Belletti et al., 2012). However, it is unclear whether this configuration should pattern with disjunction or with intersection in acceptability judgments. Additionally, this does not address the concern that example (7) becomes a case of intersection with the addition of these features. It is still unclear why sentences like (7) are consistenly more acceptable than the other cases of inclusion included in our experiments.
}

than the distinctness of morpho-syntactic features) predicts the distribution of $w h$-island amelioration effects.

We suggest that participants in these experiments were able, to varying degrees, to use semantic distinctness, rather than morphosyntactic distinctness, as a strategy for interpreting illformed $w h$-island examples. First, we will adopt a broadly Hamblin semantics of wh-questions, and assume that (i) questions denote a set of possible answers (Hamblin, 1973; see also Karttunen, 1977, and many others), and (ii) wh-phrases denote a set of potential referents (Hamblin, 1973; Kratzer and Shimoyama, 2002). Intuitively, the set of referents for the whitem in a single-wh question corresponds to possible fragment $\mathrm{NP}$ answers to that question. Under this family of assumptions, bare $w h$-phrases like who denote the set of all human individuals, whereas a D-linked wh-phrase like which award would denote a presupposed set of entities satisfying the NP restrictor, in this case award, and require the answer to the wh-question to be constructed from some referent in this set only. With these assumptions, let us examine the distinctness of sets of individuals or objects denoted by wh-phrases in Table 10, which illustrates the main feature configurations that were investigated in our acceptability judgment experiments.

In the bare identity condition with who as an extracted whphrase, both the extracted $w h$-phrase and the intervener denote the set of all humans, and therefore their domains are identical and non-distinct. If the extracted wh-phrase is what, we assume that what denotes a set of everything in the world, which includes human individuals. ${ }^{5}$ Here, the set denoted by what is a superset of the set denoted by who, and these sets are thus overlapping. As for the inclusion configuration with animate wh-phrases, which visitor denotes a presupposed set of visitors, while who denotes a set of all human individuals. Thus, the sets of individuals denoted by these two wh-phrases are also overlapping. On the other hand, for the inclusion configuration with inanimate and animate whphrases, the set denoted by which event and the set denoted by who are distinct. This explains the amelioration effect that was observed in the comparison of Experiments 2 and 3. Finally, in the D-linked identity conditions, the sets of individuals or objects denoted by the two wh-phrases (which visitor and which family, or which event and which family) are clearly distinct. Thus, these observations lead to the generalization that the wh-island violations that were amenable to amelioration effects were those in which the sets denoted by the extracted wh-phrase and the intervener are distinct. We take this as a necessary condition for wh-island amelioration.

\footnotetext{
${ }^{5}$ There are three empirical reasons for assuming that what is underspecified for human or animacy features, and therefore is able to denote humans (see Grosu, 2003). First, what can be combined with either animate or inanimate nouns to form complex wh-phrases (e.g., What doctor did you see? What textbook did you buy?), whereas this type of composition is not possible for wh-phrases like who with clear human and animacy feature specification (*who doctor). Second, the answer to what can be human or non-human, especially when there are multiple answers (e.g., What can you see? John, Mary, and a tree.). This is not possible for wh-phrases that are specified for human features (e.g., Who did you see? *John, Mary, and a tree.). Third, free relative clauses with what can take a human or a non-human referent (Grosu, 2003). In a sentence like What I thought was a policeman was just a log, the wh-phrase what is treated as human (a policeman) internally to the free relative clause, whereas it is treated as inanimate (a log) externally.
} 
TABLE 10 | Distribution of amelioration effects and semantic distinctness.

\begin{tabular}{llll}
\hline Conditions & Sentence & Amelioration? & $\begin{array}{l}\text { Semantic } \\
\text { distinctness }\end{array}$ \\
\hline Bare identity & $\begin{array}{l}\text { Who/what did you } \\
\text { wonder who would } \\
\text { host_? }\end{array}$ & No & Non-distinct \\
Inclusion (animate) & $\begin{array}{l}\text { Which visitor did you } \\
\text { wonder who would } \\
\text { host_? }\end{array}$ & No & Non-distinct \\
Inclusion (inanimate) & $\begin{array}{l}\text { Which event did you } \\
\text { wonder who would } \\
\text { host_? }\end{array}$ & Maybe? & Distinct \\
D-linked identity & $\begin{array}{l}\text { Which visitor did you } \\
\text { wonder which family } \\
\text { would host_? }\end{array}$ & Yes & \\
Which event did you & Yes & Distinct \\
Donder which family & & Distinct \\
would host_? & & \\
\hline
\end{tabular}

The semantic distinctness of the wh-phrases provides the beginnings of an explanation of many of the patterns in our data, but clearly we do not have evidence for any sort of categorical amelioration; in fact, our results could be taken as evidence against it. One possible explanation for this state of affairs is that similarity-based interference during memory retrieval operations is sensitive to the semantic distinctness of two whphrases. As noted in the Introduction, it has been widely observed that the processing of filler-gap dependencies can be impeded when the dependencies contain two similar NPs. This similarity interference effect is considered to follow from limitations of the memory system in either encoding two similar NPs as distinct items, or in retrieving the target NPs with accurate syntactic and semantic features. It is plausible that the semantic distinctness of wh-phrases modulates the ease of encoding or retrieval processes, and when these processes are readily performed, participants may perceive the $w h$-island violations to be less severely degraded. In this sense, the semantic distinctness of $w h$-phrases may serve as a formal characterization of NPs that are particularly confusable for memory operations.

This psycholinguistic explanation for the role of semantic distinctness and memory constraints has implications for theories of islands and syntactic amelioration effects in general. We suggest two potential approaches for integrating syntactic and psycholinguistic constraints, both of which are equally compatible with our findings. The first approach is to reduce island constraints to cognitive constraints on memory operations, such that "island violations" merely reflect difficulties in establishing wh-dependencies during real-time parsing (Kluender and Kutas, 1993; Hofmeister and Sag, 2010; for related explanations for Superiority effects, see Hofmeister et al., 2013). With respect to wh-islands, according to this reductionist approach, what used to be considered violations of Featural RM constraints would be reanalyzed as severe instances of similarity-based interference effects, which are sensitive to both syntactic and semantic features of retrieval candidates. Simplifying the theory of grammar and postulating fewer constraints that are specific to linguistic representations is a welcome result (Chomsky, 1995; Phillips, 2013), and it highlights how syntactic theories can be refined by a further collaboration between linguistics and broader cognitive science research. The future agenda for this approach includes extension of experimental investigations to other syntactic phenomena that Featural RM provided explanations for (e.g., intervention effects in combien extraction in French; Obenauer, 1983, 1994), as well as addressing counter-arguments for cognitive explanations of island constraints (Sprouse et al., 2012; see also Phillips, 2006). We leave these questions for future research.

The second approach for integrating syntactic constraints on wh-dependency formation and memory constraints is to situate similarity interference effects in repair processes that the parser initiates in order to cope with a violation of formal, syntactic constraints; we term this approach the Ameliorationas-Repair hypothesis. This explanation of amelioration effects relies on the following three assumptions. First, we assume that acceptability judgment intuitions minimally reflect the wellformedness of syntactic derivations and semantic representations that the parser assigns to a given sentence. When this process fails due to linguistic or other cognitive constraints, we perceive degradation in sentence acceptability (Schütze, 1996), and the severity of degradation reflects the number of constraint violations at all levels of representations (Legendre et al., 1991; Keller, 2000; Smolensky and Legendre, 2006; Haegeman et al., 2014). Second, we also assume that syntactic constraints on $w h$-islands do play an important role in accounting for the general acceptability degradation due to extraction out of whislands, and this constraint could be the original Relativized Minimality constraint in Rizzi (1990, 2004) which did not distinguish bare identity $w h$-island from inclusion $w h$-island. Finally, we also assume that in the face of sentences that violate syntactic constraints, the parser attempts to repair the structure in order to assign an interpretation to the structurally unintegrated $w h$-phrase. Such interpretive repair processes are well documented in the psycholinguistics literature on severe garden-path sentences (e.g., Christianson et al., 2001; Ferreira and Patson, 2007). While this style of repair may not "cancel" the initial violation of syntactic constraints, it would at least provide a strategy for obtaining a legitimate semantic representation for the sentence that can be passed onto the interpretive process.

Given these assumptions, acceptability judgment data should reflect the degree to which this repair process is able to (a) identify a gap position inside an island, and (b) retrieve the relevant $w h$ phrase in order to complete the wh-dependency for the semantic representation. Under the Amelioration-as-Repair approach, it is during this repair/retrieval process that the similarity interference effects arise. It is well known that the parser typically respects island constraints during real-time sentence processing (e.g., Stowe, 1986; Traxler and Pickering, 1996); thus, initially the parser should generate an ungrammatical structure with no gap for the wh-phrase. This syntactic violation initiates the repair process, and the search for a gap inside an island. This search process identifies a verb with a missing complement, which indicates that the verb could be a host for the gap. This gap identification subsequently triggers a retrieval of a wh-phrase, 
using the thematic role and morphological features as retrieval cues. $^{6}$ This retrieval process should be sensitive to the semantic distinctness of $w h$-phrases. If the repair process fails due to similarity interference effects (e.g., in the bare identity condition), the semantic representation would veridically reflect the syntactic violation of the wh-island constraint (i.e., no gap for the whphrase), and the sum of these two violations results in more severe degradation. On the other hand, if the parser identifies a gap inside an island due to the lack of similarity interference effects (e.g., in D-linked identity conditions with semantically distinct $w h$-phrases), the resulting semantic representation no longer contains any violation, even though it is derived from a structure that does, and therefore the only source of acceptability degradation is the initial violation of the $w h$-island constraint (see Huang, 1982 for arguments that the semantic representation of islands with argument gaps does not incur any violation).

One consequence of the Amelioration-as-Repair hypothesis is that it provides a new direction toward a mechanistic understanding of acceptability judgment in general. To this day, even though acceptability judgment data has served as the primary source of data for linguists, there is very little theory of how such intuitions arise (cf. Schütze, 1996), or how the process of judging sentence acceptability reflects psycholinguistic constraints. As such, regardless of whether island constraints or Featural RM should remain as a formal constraint on linguistic representations, integration of perspectives and insights from psycholinguistics could help advance the field of syntax.

Finally, we note that either approach raises new research questions that need to be addressed in future research. First, the current study does not provide time course measures that shed light on the memory encoding and retrieval mechanisms that are assumed under either explanation. Second, it remains to be answered why the animacy-based modulation of wh-island amelioration effects was not reliably observed across experiments. Following the psycholinguistic explanations above, we tentatively suggest that the real-time encoding and comparison of semantic distinctness information could be subject to a

\footnotetext{
${ }^{6}$ It is also plausible that the animacy effect observed in our experiments reflects the fit of the verb semantic retrieval cues and the wh-phrases (e.g., event may be a better object for host than visitor). Testing this hypothesis requires a careful control of verb-noun co-occurrence frequency and plausibility. We leave this question open for future research.
}

\section{REFERENCES}

Alexopoulou, T., and Keller, F. (2007). Locality, cyclicity, and resumption: at the interface between the grammar and the human sentence processor. Language 83, 110-160. doi: 10.1353/lan.2007.0001

Alexopoulou, T., and Keller, F. (2013). "What vs. who and which: kind-denoting fillers and the complexity of whether-islands," in Experimental Syntax and Island Effects, eds J. Sprouse and N. Hornstein (Baltimore, MD: Cambridge University Press), 310-340.

Baayen, R. H., Davidson, D. J., and Bates, D. M. (2008). Mixed-effects modeling with crossed random effects for subjects and items. J. Mem. Lang. 59, 390-412. doi: 10.1016/j.jml.2007.12.005

Bates, D., Maechler, M., Bolker, B., and Walker, S. (2015). Ime4: Linear MixedEffects Models using Eigen and S4. R Package Version 1.1-9. Available at: https:// CRAN.R-project.org/package $=\operatorname{lme} 4$ variety of conceptual or cognitive factors that will then impact the behavior of amelioration. For example, accessing the set of all individuals denoted by who may be inherently complex when it is presented out of context, as in the current experiments. This difficulty may sometimes mask the potential advantage of semantic distinctness in the inclusion configuration with an inanimate $w h$-phrase, suggesting also that it may not be generally safe to test amelioration effects out of context.

\section{CONCLUSION}

The present study investigated the distribution of wh-island amelioration effects, with a special focus on how it is modulated by morpho-syntactic features and semantic features of wh-phrases. We found that morpho-syntactic features alone, such as those to which Featural RM in its current form appeals, failed to account for the distribution of wh-island amelioration effects. We suggested that a full explanation of our results requires the consideration of semantic representations, which may, in turn, be related to constraints on the sentence processing mechanisms that give rise to similarity interference effects. This observation calls for future work that re-examines amelioration effects in other syntactic environments in light of constraints on sentence processing mechanisms.

\section{ACKNOWLEDGMENTS}

This work was supported in part by NSF BCS-1423117 to AO, and NSF BCS-1344269 to KR and AO. Our thanks to Eleanor Chodroff and Bob Wiley for their contributions to Experiment 1.

\section{SUPPLEMENTARY MATERIAL}

The Supplementary Material for this article can be found online at: http://journal.frontiersin.org/article/10.3389/fpsyg. 2015.02048

Belletti, A., Friedmann, N., Brunato, D., and Rizzi, L. (2012). Does gender make a difference? Comparing the effect of gender on children's comprehension of relative clauses in Hebrew and Italian. Lingua 122, 1053-1069. doi: 10.1016/j.lingua.2012.02.007

Bentea, A., and Durrleman, S. (2014). "Children don't like restrictions: evidence from the acquisition of object A'-dependencies in French," in Proceedings of the 39th Annual Boston University Conference on Language Development, Boston, MA.

Boeckx, C., and Jeong, Y. (2003). "The fine structure of syntactic intervention," in Proceedings of the Thirty-First Western Conference on Linguistics, Vol. 14, eds B. Agbayani, P. Koshkinen, and V. Samiian (Fresno, CA: California State University, Department of Linguistics Publications), 33-41.

Chomsky, N. (1964). Current issues in Linguistic Theory. Hague: Mouton.

Chomsky, N. (1977). "On wh-movement," in Formal Syntax, eds P. Culicover, T. Wasow, and A. Akmajian (New York, NY: Academic Press), 71-132. 
Chomsky, N. (1995). The Minimalist Program. Cambridge, MA: MIT Press.

Christianson, K., Hollingworth, A., Halliwell, J. F., and Ferreira, F. (2001). Thematic roles assigned along the garden path linger. Cogn. Psychol. 42, 368-407. doi: 10.1006/cogp.2001.0752

Cinque, G. (1990). Types of A'-dependencies. Linguistic Inquiry Monographs 17. Cambridge, MA: MIT Press.

Comorovski, I. (1996). Interrogative Phrases and the Syntax-Semantics Interface. New York, NY: Springer.

Fanselow, G., Schlesewsky, M., Vogel, R., and Weskott, T. (2011). Animacy effects on crossing wh-movement in German. Language 494, 657-683.

Featherston, S. (2005). That-trace in German. Lingua 115, 1277-1302. doi: 10.1016/j.lingua.2004.04.001

Ferreira, F., and Patson, N. D. (2007). The "good enough" approach to language comprehension. Lang. Linguist. Compass 1, 71-83. doi: 10.1111/j.1749818X.2007.00007.x

Friedmann, N., Belletti, A., and Rizzi, L. (2009). Relativized relatives: types of intervention in the acquisition of A' dependencies. Lingua 119, 67-88. doi: 10.1016/j.lingua.2008.09.002

Gibson, E., Piantadosi, S., and Fedorenko, K. (2011). Using mechanical Turk to obtain and analyze English acceptability judgments. Lang. Linguist. Compass 5 , 509-552. doi: 10.1111/j.1749-818X.2011.00295.x

Gibson, E., and Thomas, J. (1999). Memory limitations and structural forgetting: the perception of complex ungrammatical sentences as grammatical. Lang. Cogn. Process. 14, 225-248. doi: 10.1080/016909699386293

Goodall, G. (2015). The D-linking effect on extraction from islands and nonislands. Front. Psychol. 5:1493. doi: 10.3389/fpsyg.2014.01493

Goodluck, H. (2010). Object extraction is not subject to Child Relativized Minimality. Lingua 120, 1516-1521. doi: 10.1016/j.lingua.2009.10.005

Gordon, P. C., Hendrick, R., and Johnson, M. (2001). Memory interference during language processing. J. Exp. Psychol. 27, 1411-1423.

Gordon, P. C., Hendrick, R., and Johnson, M. (2004). Effects of noun phrase type on sentence complexity. J. Mem. Lang. 51, 97-114. doi: 10.1016/j.jml.2004.02.003

Gordon, P. C., Hendrick, R., Johnson, M., and Lee, Y. (2006). Similarity-based interference during language comprehension: evidence from eye tracking during reading. J. Exp. Psychol. 32, 1304-1321.

Gordon, P. C., Hendrick, R., and Levine, W. H. (2002). Memory-load interference in syntactic processing. Psychol. Sci. 13, 425-430. doi: 10.1111/1467-9280. 00475

Grohmann, K. K. (2000). Prolific Peripheries: A Radical View from the Left. Doctoral dissertation, University of Maryland, College Park, MD.

Grosu, A. (2003). A unified theory of 'standard' and 'transparent' free relatives. Nat. Lang. Linguist. Theory 21, 247-331. doi: 10.1023/A:1023387128941

Haegeman, L., Jiménez-Fernández, A., and Radford, A. (2014). Deconstructing the subject condition in terms of cumulative constraint violation. Linguist. Rev. 31, 73-150. doi: 10.1515/tlr-2013-0022

Hamblin, C. L. (1973). Questions in montague English. Found. Lang. 10, 41-53.

Hofmeister, P. (2011). Representational complexity and memory retrieval in language comprehension. Lang. Cogn. Process. 26, 376-405. doi: 10.1080/01690965.2010.492642

Hofmeister, P., Jaeger, T. F., Arnon, I., Sag, I. A., and Snider, N. (2013). The source ambiguity problem: distinguishing the effects of grammar and processing on acceptability judgments. Lang. Cogn. Process. 28, 48-87. doi: 10.1080/01690965.2011.572401

Hofmeister, P., and Sag, I. A. (2010). Cognitive constraints and island effects. Language 86, 366-415. doi: 10.1353/lan.0.0223

Hofmeister, P., and Vasishth, S. (2014). Distinctiveness and encoding effects in online sentence comprehension. Front. Psychol. 5:1237. doi: 10.3389/fpsyg.2014.01237

Huang, C. J. (1982). Logical Relations in Chinese and the Theory of Grammar. Doctoral dissertation, Cambridge, MA: MIT Press.

Karttunen, L. (1977). Syntax and semantics of questions. Linguist. Philos. 1, 1-44. doi: $10.1007 / \mathrm{BF} 00351935$

Keller, F. (2000). Gradience in Grammar: Experimental and Computational Aspects of Degrees of Grammaticality. Doctoral dissertation, University of Edinburgh, Edinburgh.

Kluender, R., and Kutas, M. (1993). Subjacency as a processing phenomenon. Lang. Cogn. Process. 8, 573-633. doi: 10.1080/01690969308407588
Kratzer, A., and Shimoyama, J. (2002). "Indeterminate pronouns: the view from Japanese," in Proceedings of the Third Tokyo Conference on Psycholinguistics, ed. Y. Otsu (Tokyo: Hituzi Syobo), 1-25.

Kush, D., Johns, C. L., and Van Dyke, J. A. (2015). Identifying the role of phonology in sentence-level reading. J. Mem. Lang. 79, 18-29. doi: 10.1016/j.jml.2014.11.001

Kuznetsova, A., Brockhoff, B., and Christensen, H. B. (2015). lmerTest: Tests in Linear Mixed Effects Models. R Package Version 2.0-29. Available at: http:// CRAN.R-project.org/package $=$ lmerTest

Legendre, G., Miyata, Y., and Smolensky, P. (1991). "Unifying syntactic and semantic approaches to unaccusativity: A connectionist approach," in Proceedings of the Seventeenth Annual Meeting of the Berkeley Linguistics Society: General Session and Parasession on The Grammar of Even Structure, Vol. 17, eds C. Johnson, L. A. Sutton, and R. Shields (Berkeley, CA: University of California, Berkley Linguistics Society), $156-167$.

Lewis, R. L., and Vasishth, S. (2005). An activation-based model of sentence processing as skilled memory retrieval. Cogn. Sci. 29, 375-419. doi: 10.1207/s15516709cog0000_25

McDaniel, D., and Cowart, W. (1999). Experimental evidence for a minimalist account of English resumptive pronouns. Cognition 70, B15-B24. doi: 10.1016/S0010-0277(99)00006-2

Obenauer, H. (1983). On the Identification of empty categories. Linguist. Rev. 4, 153-202.

Obenauer, H. (1994). Aspects de la Syntaxe A-barre. Doctoral dissertation, Université de Paris VIII, Paris.

Pesetsky, D. (1987). "Wh-in-situ: movement and unselective binding," in The Representation of in Definiteness, eds E. J. Reuland and A. G. B. ter Meulen (Cambridge, MA: MIT Press), 98-129.

Pesetsky, D. M. (2000). Phrasal Movement and its Kin. Cambridge, MA: MIT press. Phillips, C. (2006). The real-time status of island phenomena. Language 82, 795823. doi: 10.1353/lan.2006.0217

Phillips, C. (2013). Some arguments and nonarguments for reductionist accounts of syntactic phenomena. Lang. Cogn. Process. 28, 156-187. doi: 10.1080/01690965.2010.530960

Rappaport, G. C. (2003). "The grammatical role of animacy in a formal model of Slavic morphology," in American Contributions to the Thirteenth International Congress of Slavists (Ljubljana, 2003), Vol. 1, eds R. A. Maguire and A. Timberlake (Bloomington, IN: Slavica), 149-166.

R Core Development Team (2015). R: A Language and Environment for Statistical Computing. Vienna: R Foundation for Statistical Computing.

Rizzi, L. (1990). Relativized Minimality. Cambridge, MA: MIT Press.

Rizzi, L. (2004). "Locality and left periphery," in Structures and Beyond: The Cartography of Syntactic Structures, Vol. 3, ed. A. Belletti (Oxford: Oxford University Press), 223-251.

Rizzi, L. (2013). Locality. Lingua. 130, 169-186. doi: 10.1016/j.lingua.2012.12.002

Ross, J. R. (1967). Constraints on Variables in Syntax. Doctoral dissertation, Massachusetts Institute of Technology, Cambridge.

Schütze, C. T. (1996). The Empirical Base of Linguistics: Grammaticality Judgments and Linguistic Methodology. Chicago: University of Chicago Press.

Schütze, C. T., and Sprouse, J. (2013). "Judgment data," in Research Methods in Linguistics, eds R. J. Podesva and D. Sharma (New York, NY: Cambridge University Press), 27-50.

Shields, R. (2008). What's So Special about D-Linking? Poster Session Presented at NELS 39. New York, NY: Cornell University.

Smolensky, P., and Legendre, G. (2006). The Harmonic Mind: From Neural Computation to Optimality-Theoretic Grammar. Vol. 1: Cognitive Architecture; vol. 2: Linguistic and Philosophical Implications. Cambridge, MA: MIT Press.

Sprouse, J. (2011). A validation of Amazon Mechanical Turk for the collection of acceptability judgments in linguistic theory. Behav. Res. Methods 43, 155-167. doi: $10.3758 /$ s13428-010-0039-7

Sprouse, J., and Hornstein, N. (2013). Experimental Syntax and Island Effects. Cambridge: Cambridge University Press.

Sprouse, J., Wagers, M., and Phillips, C. (2012). A test of the relation between working-memory capacity and syntactic island effects. Language 88, 82-123. doi: $10.1353 /$ lan.2012.0029 
Starke, M. (2001). Move Reduces to Merge: A Theory of Locality. Doctoral dissertation, University of Geneva, Geneva.

Stowe, L. E. (1986). Parsing WH-constructions: evidence for on-line gap location. Lang. Cogn. Process. 1, 227-245. doi: 10.1080/016909686084 07062

Traxler, M. J., and Pickering, M. J. (1996). Plausibility and the processing of unbounded dependencies: an eye-tracking study. J. Mem. Lang. 35, 454-475. doi: 10.1162/jocn.1993.5.2.196

Van Dyke, J. A., and Johns, C. L. (2012). Memory interference as a determinant of language comprehension. Lang. Linguist. Compass 6, 193-211. doi: $10.1002 / \operatorname{lnc} 3.330$

Van Dyke, J. A., and McElree, B. (2006). Retrieval interference in sentence comprehension. J. Mem. Lang. 55, 157-166. doi: 10.1016/j.jml.2006. 03.007

Vasishth, S., Suckow, K., Lewis, R. L., and Kern, S. (2010). Short-term forgetting in sentence comprehension: crosslinguistic evidence from verbfinal structures. Lang. Cogn. Process. 25, 533-567. doi: 10.1080/016909609033 10587

Villata, S., Rizzi, L., and Franck, J. (in press). Intervention effects in weak islands and Relativized Minimality: new experimental evidence from graded judgments Lingua.
Warren, T., and Gibson, E. (2002). The influence of referential processing on sentence complexity. Cognition 85, 79-112. doi: 10.1016/S0010-0277(02) 00087-2

Warren, T., and Gibson, E. (2005). Effects of NP type in reading cleft sentences in English. Lang. Cogn. Process. 20, 751-767. doi: 10.1080/01690960500051055

Conflict of Interest Statement: The authors declare that the research was conducted in the absence of any commercial or financial relationships that could be construed as a potential conflict of interest.

The reviewer, Dario Leander Jim Felix Paape, and handling editor declared their shared affiliation, and the handling editor states that the process nevertheless met the standards of a fair and objective review.

Copyright (c) 2016 Atkinson, Apple, Rawlins and Omaki. This is an open-access article distributed under the terms of the Creative Commons Attribution License (CC BY). The use, distribution or reproduction in other forums is permitted, provided the original author(s) or licensor are credited and that the original publication in this journal is cited, in accordance with accepted academic practice. No use, distribution or reproduction is permitted which does not comply with these terms. 